\title{
VECTORCARDIOGRAPHY IN MYOCARDIAL INFARCTION
}

\author{
BY \\ G. HOWITT* AND T. D. V. LAWRIE \\ From the Department of Cardiology, Royal Infirmary, Glasgow \\ Received April 24, 1959
}

Standard limb leads and unipolar electrocardiography can provide valuable information in the diagnosis of myocardial infarction but there are occasions when the cardiographic changes are inconclusive. It may be difficult to differentiate between pericarditis and myocardial infarction. The electrocardiographic changes in posterior or lateral infarction are not always characteristic. It is not always possible to decide whether there has been a fresh infarct superimposed on $(a)$ a previous infarct, $(b)$ left ventricular hypertrophy, or $(c)$ bundle-branch block. An unusual anatomical position of the heart can lead to great difficulties in the interpretation of electrocardiographic changes.

The introduction of improved cathode ray oscilloscopes has led to a renewed interest in vectorcardiography and a hope that, either alone or in conjunction with electrocardiography, it might throw fresh light on the diagnosis of myocardial infarction. Up to the present, however, there have been conflicting opinions as to its comparative value.

\section{MATERIAL AND MethodS}

The present article describes our attempts to assess the value of vectorcardiography in 50 cases of myocardial infarction. These were diagnosed on generally accepted clinical and electrocardiographic criteria (Myers et al., 1949; and Goldberger, 1957) and were made up as follows:

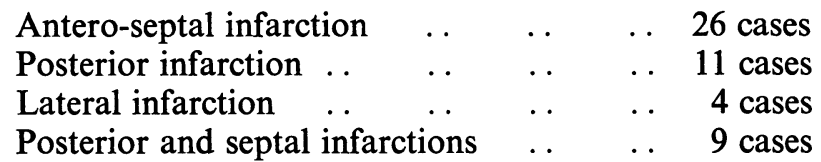

In addition, 50 subjects with no evidence of heart disease and with normal electrocardiograms were included.

The instrument used was the Cambridge vectorcardiograph. In each case static and deroule vectorcardiograms were recorded using a time marker interrupting the beam at 0.005 second intervals. The notation adopted was that recommended by Helm (1956) (Fig. 1). The electrode placings were those of the Cube system (Grishman and Scherlis, 1952); and the records were taken with the patient supine and in quiet respiration.

The following measurements were made and features noted in all three planes.

1. QRS Loop. (i) Maximum Vector. The distance between the null point and the furthermost point on the loop.

(ii) Maximum Width. The widest part of the loop measured in an axis at right angles to the maximum vector.

(iii) $Q R S$ Angle. The angle between the $\mathrm{xx}^{\prime}$ axis and the maximum vector.

* Present address-Department of Cardiology, Royal Infirmary, Manchester. 


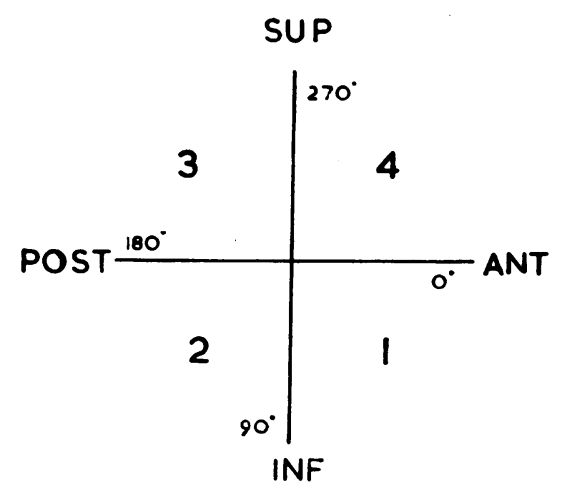

SAGITTAL

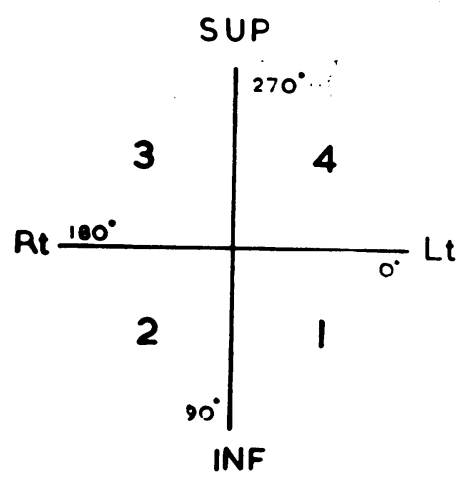

FRONTAL

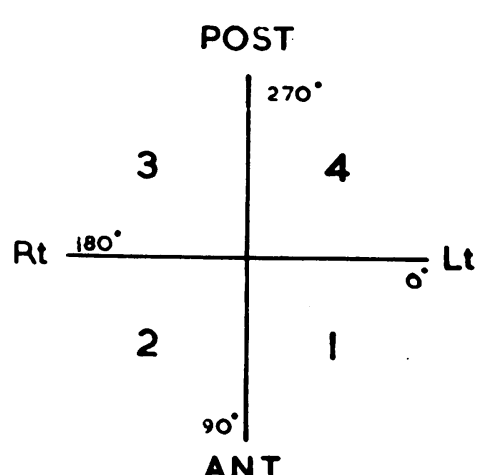

HORIZONTAL

Fig. 1.-System of notation (Helm, 1956).

(iv) Initial, Terminal, and Body Forces (Young et al., 1956). Initial forces are present if the initial portion of the loop lies to the right and/or superior to the null point. These correspond generally to Q waves in I, V6, and aVF. Similarly, terminal forces are defined as the terminal portion of the loop which lies to the right and/or superior to the null point and these correspond generally to the $S$ wave in I, V6, and aVF. The portions of the QRS loop not covered by these terms are referred to as "body" forces. When the initially inscribed portion of the loop does not satisfy the criteria for 'initial' forces these early forces form part of the 'body' forces.

(v) Direction of rotation of the earliest part and of the main body of the loop.

(vi) Direction of 0.010 and $0.015 \mathrm{sec}$. Vectors. In each case, this is the angle between the $\mathrm{xx}^{\prime}$ axis and a line joining the null point to the point on the loop reached at 0.010 and 0.015 seconds.

(vii) The ratio of the magnitude of the superiorly orientated initial forces to the ensuing inferior forces (frontal and sagittal planes) and for the initial rightward to the leftward forces (horizontal plane).

(viii) Determination of the Plane of the QRS Loop. 
2. T Loop. (i) Maximum Vector. The distance between the null point and the furthermost point on the loop.

(ii) $T$ Angle. The angle between the $\mathrm{xx}^{\prime}$ axis and the maximum vector.

(iii) $Q R S / T$ Angle. The difference between the QRS and $\mathrm{T}$ angles. In normal cases the axis of the T loop usually lies in a clockwise direction from the axis of the QRS loop in the frontal and horizontal planes, and in a counterclockwise direction in the sagittal planes. For descriptive purposes, it was decided to limit the QRS/T angle to $180^{\circ}$ or less. When measured in a clockwise direction the QRS/T angle was regarded as positive in the frontal and horizontal planes and negative in the sagittal plane; when measured in a counterclockwise direction it was regarded as negative in the frontal and horizontal planes and positive in the sagittal plane.

(iv) Rotation. Direction of rotation of the loop. In several cases the loop was seen in the frontal or sagittal plane as a straight line, the afferent and efferent limbs being superimposed.

\section{RESULTS}

Antero-septal Infarction (26 cases). The early forces in normal subjects are directed to the right and anteriorly, but in antero-septal infarction these forces are lost, due to death of tissue on the anterior and septal portions of the myocardium; the spatial loop is, therefore, directed posteriorly and to the left. These features are best seen in the horizontal plane and here the posterior displacement of the efferent limb of the loop gives rise to a rather narrow loop in many cases (Fig. 2). In 4 cases, there were initial forces anteriorly and to the right in the horizontal plane corresponding to a small R wave in V1, but the loop then turned sharply posteriorly and to the left corresponding to QS complexes in V2, V3, and V4. Whereas, in the normal horizontal loop the QRS and T loops are both inscribed counterclockwise, in this group the loops were frequently inscribed in a clockwise direction and in 14 cases the two loops were inscribed in opposite direction.

The loss of initial rightward forces was seen in the frontal plane and the loss of anteriorly directed forces in the sagittal plane. The range of values for the QRS/T angle was greater than normal in all three planes.

There was good correlation between the vectorcardiogram and the electrocardiogram as regards QRS complexes but in three cases the correlation between $T$ loop and $T$ wave in the horizontal plane was poor, mainly because of the small size of the T loop.

Posterior Infarction (11 cases). According to vectorcardiographic description, this type of infarction is more accurately termed inferior myocardial infarction, because it affects the inferior (or diaphragmatic) surface of the heart.

The diagnostic features in this group are seen in the sagittal and frontal planes. The horizontal plane, being at right angles to the electrical forces of the involved surface, is unaffected (Fig. 2).

The main diagnostic feature was the superior orientation of the early forces in the sagittal and frontal planes. The ratio of the magnitude of these forces to the ensuing inferiorly directed forces

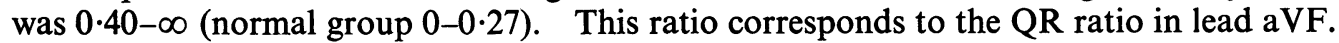

In 9 out of the 11 cases, the contour of the QRS loop was abnormal with delay, notching, or abrupt changes in direction. These features are considered to be in keeping with disturbances of conduction which occur frequently in inferior infarction.

There was good correlation between the vectorcardiogram and electrocardiogram as regards the QRS loop but in two cases the T loop correlation was poor.

Postero-septal Infarction ( 9 cases). In this group the diagnostic features are a combination of those found in antero-septal and posterior infarction. There are characteristic abnormalities in all three planes.

In the horizontal plane there was absence or clockwise rotation of initial anterior forces, with posterior displacement of the efferent limb of the QRS loop.

In the sagittal plane abnormal initial superior forces directed posteriorly and inscribed in a 
counter-clockwise direction were the main features. In the frontal plane, the abnormal superior forces were directed mainly to the left.

In three cases the changes of septal infarction were more obvious in the electrocardiogram than in the vectorcardiogram, but in these the T loop correlation was poor.

Lateral Infarction (4 cases). The diagnostic features are seen in the horizontal and frontal planes. In this type of infarction there is loss of forces on the lateral (left) surface of the heart; as a result the forces to the right are of greater magnitude than normal, corresponding to a large $Q$ wave in leads I, aVL, and V6 (Fig. 2).

In this group the ratio of initial rightwaird to ensuing leftward forces (horizontal plane) was $0 \cdot 3-2 \cdot 0$ (normal $0-0 \cdot 224$ ). In all four cases there was good correlation with the electrocardiogram.

The details of results are recorded in Tables I, V, VI, and VII.

\section{DisCUSSION}

There are, at present, three major problems confronting workers in the field of vectorcardiography: (a) the reference system, (b) the method of analysis, and (c) the system of notation.

There is considerable divergence of opinion as to what constitutes the best reference system. 
TABLE I

Measurements of Vector LoOps in 50 Normal Subjects

\begin{tabular}{ll|c|c|c}
\hline & & Frontal & Horizontal & Sagittal \\
\hline Maximum QRS vector (millivolts) &. & $13 \cdot 6-20 \cdot 0$ & $3 \cdot 2-19 \cdot 4$ & $1 \cdot 4-11 \cdot 9$ \\
\hline Maximum QRS width (millivolts) &.. & $5 \cdot 2-21 \cdot 4$ & $1 \cdot 0-12 \cdot 4$ & $1 \cdot 0-8 \cdot 1$ \\
\hline Maximum T vector (millivolts) &. & $0 \cdot 8-10 \cdot 4$ & $1 \cdot 2-5 \cdot 7$ & $0 \cdot 8-5 \cdot 2$ \\
\hline
\end{tabular}

It is generally agreed that those systems in current use are "incorrect", and it is desirable to have a "correct" system that will give a more accurate representation of the spatial loop, without being too cumbersome for practical purposes. Such a system has not yet been agreed upon, so it was decided to use one of the less accurate systems, namely the cube system.

The systems used for reporting or analysis of electrocardiograms are unsuitable for the study of vectorcardiograms. It is usual to analyse vectorcardiograms either by noting qualitative features or by making quantitative measurements of certain portions of the loop. Where there is considerable abnormality in vectorcardiograms, qualitative changes in the configuration of the loops are easily recognized, and, when the abnormalities are characteristic, there is no difficulty in diagnosis, e.g. ventricular hypertrophy or myocardial infarction. More accurate interpretation of the abnormal vectorcardiograms will not be possible until quantitative measurements are available.

Quantitative measurements of vector loops by reference systems that are electrically inaccurate cannot themselves be accurate, but it does not follow that they are valueless, and some attempt at quantitative assessment should be made. An infinite number of measurements of vector loops could be made, and we have to select some to determine whether they give sufficient diagnostic information or not. There is at present no general agreement as to which measurements are likely to yield the most useful information.

Initial Forces. Some workers attach great significance to the initial forces. Duchosal and Sulzer (1949) believe that, in myocardial infarction, the main changes are to be found in the initial forces of the QRS loop. Young et al. (1956) after a study of 30 cases of inferior myocardial infarction considered that all had abnormal, superiorly orientated forces, during the initial stages of ventricular depolarization; these changes involve magnitude, direction, and duration.

Grishman and Scherlis (1952) detailed their qualitative criteria for the diagnosis of diaphragmatic, posterior, antero-septal anterior, antero-lateral, and combined infarcts. These were based on the assumption that "whenever a significantly large area of myocradium becomes electrically inert, as with myocardial infarction, there is loss of electromotive forces normally contributed by that area during the spread of the wave of accession".

If this view is accepted, the vector loop in myocardial infarction will assume a new spatial position, diametrically opposite to the involved portions, and the entire loop will be affected in this way. Even so, variation in magnitude or form of the initial forces can be of value in the diagnosis of myocardial infarction. Here again we meet with difficulty as there is no general acceptance as to what are "initial forces".

The definition adopted in the present investigation is useful, since it reflects the presence of abnormal $\mathrm{Q}$ waves occurring in most cases of myocardial infarction. Nevertheless, while it is natural to try to relate the vectorcardiogram to the electrocardiogram, it is desirable to have a method of analysis that is independent of electrocardiography.

Another method of estimation of initial forces is to measure the angle between the $\mathrm{xx}^{\prime}$ axis and a line joining the null point to a point on the loop reached at a specified time. The results are recorded in Table II. The value of this measurement varies according to the site of infarction.

Antero-septal Infarction. In the horizontal plane, it was seen that, in the case of the direction of the 0.010 second vector, there was an overlap with the normal group; this was not so in the 
TABLE II

Direction OF THe 0.010 Sec. AND 0.015 Sec. Vectors

\begin{tabular}{|c|c|c|c|}
\hline Group & Plane & $0.010 \mathrm{sec}$. vector & $0.015 \mathrm{sec}$. vector \\
\hline $\begin{array}{lll}\text { Normal } \ldots & \ldots\end{array}$ & $\begin{array}{l}\mathrm{F} \\
\mathrm{H} \\
\mathrm{S}\end{array}$ & $\begin{array}{r}0^{\circ}-356^{\circ} \\
151^{\circ}-15^{\circ} \\
305^{\circ}-90^{\circ}\end{array}$ & $\begin{array}{r}0^{\circ}-356^{\circ} \\
145^{\circ}-0^{\circ} \\
300^{\circ}-93^{\circ}\end{array}$ \\
\hline Posterior (Inferior) infarction... & $\begin{array}{l}\mathrm{F} \\
\mathrm{H} \\
\mathrm{S}\end{array}$ & $\begin{array}{l}211^{\circ}-305^{\circ} \\
154^{\circ}-0^{\circ} \\
269^{\circ}-306^{\circ}\end{array}$ & $\begin{array}{l}218^{\circ}-352^{\circ} \\
145^{\circ}-0^{\circ} \\
260^{\circ}-293^{\circ}\end{array}$ \\
\hline Posterior and septal infarction & $\begin{array}{l}\mathrm{F} \\
\mathrm{H} \\
\mathrm{S}\end{array}$ & $\begin{array}{l}242^{\circ}-332^{\circ} \\
150^{\circ}-337^{\circ} \\
206^{\circ}-290^{\circ}\end{array}$ & $\begin{array}{l}246^{\circ}-332^{\circ} \\
180^{\circ}-337^{\circ} \\
202^{\circ}-290^{\circ}\end{array}$ \\
\hline Antero-septal infarction & $\begin{array}{l}\mathrm{F} \\
\mathrm{H} \\
\mathrm{S}\end{array}$ & $\begin{array}{l}280^{\circ}-345^{\circ} \\
150^{\circ}-320^{\circ} \\
294^{\circ}-328^{\circ}\end{array}$ & $\begin{array}{l}218^{\circ}-317^{\circ} \\
160^{\circ}-320^{\circ} \\
270^{\circ}-307^{\circ}\end{array}$ \\
\hline Lateral infarction & $\begin{array}{l}\mathrm{F} \\
\mathrm{H} \\
\mathrm{S}\end{array}$ & $\begin{array}{r}142^{\circ}-183^{\circ} \\
192^{\circ}-142^{\circ} \\
7^{\circ}-172^{\circ}\end{array}$ & $\begin{array}{r}142^{\circ}-188^{\circ} \\
186^{\circ}-145^{\circ} \\
25^{\circ}-174^{\circ}\end{array}$ \\
\hline
\end{tabular}

case of the 0.015 second vector. The "discrepancies" in the direction of the 0.010 second vector (i.e. those which overlap the normal) were due to small initial forces that curved anteriorly and to the right for a short distance, before turning sharply posteriorly in a clockwise direction not counter-clockwise as in the normal. The small initial forces corresponded to a small initial $\mathbf{R}$ wave in V1; in this small group of cases, the changes of myocardial infarction were confined to V2 and V3, or V2, V3, and V4. In the sagittal plane, this small group accounted for those vectors (both 0.010 and 0.015 seconds) that were directed anteriorly.

Posterior (Inferior) Infarction. The directions of the 0.010 second and 0.015 second vectors in the frontal plane were not outwith the normal range but were all orientated superiorly. The figures for the horizontal plane were within normal limits, as expected. The diagnostic features were seen in the sagittal plane in the case of the 0.015 second vector, the range being beyond normal.

These findings are in keeping with those previously reported by Milnor et al. (1951), using the direction of the 0.012 second vector and the tetrahedral system.

Pearce and Chapman (1957) reached a similar conclusion in a larger series of cases with pathological confirmation. Their reference system was essentially the tetrahedral system and they concluded, after studying the direction of the 0.010 second and 0.020 second vectors, that the 0.020 second vector in the sagittal plane was more accurate in the diagnosis of posterior (or inferior) myocardial infarction than the electrocardiogram. Our own series is too small to draw any definite conclusion regarding the value of 0.015 second vector using the cube system, but the findings are suggestive and worthy of further study.

Posterior and Septal Infarction. In the frontal plane, the results were within normal limits for both the 0.010 second and 0.015 second vectors. Abnormal findings were present in both the horizontal and sagittal planes. In the horizontal plane the directions of the 0.010 second and the 0.015 second vector were more posterior than normal, while in the sagittal plane, the 0.010 second and 0.015 second vectors lay in Quadrant 3, the normal vectors lying in Quadrants 4 and 1.

Lateral Infarction. In this group the results in all three planes were within normal limits for both the 0.010 second and 0.015 second vectors. The vectorcardiograms in the horizontal and the frontal planes, however, were obviously abnormal for the forces to the right, i.e. away from the site of the infarct, which is located in the left side or lateral wall of the left ventricle, were greater than normal. This is not altogether a surprising finding since the lateral wall of the left ventricle 
is probably not depolarized in the early stages of the cardiac cycle and hence the earliest forces remain unaffected.

Since the direction of the 0.010 second and 0.015 second vectors seemed to give no help in the diagnosis of lateral myocardial infarction, we considered whether measurements of the magnitude of the early forces in the vectorcardiogram might yield more useful information. These measurements were made as described and the results are given in Table III. Using these criteria, all the cases of infarction gave values outside the range of normal. It is of interest to note that in all vectorcardiograms taken, the ratio of superior to inferior forces was the same in the frontal and sagittal planes and of the rightward to leftward forces in the horizontal and frontal planes.

TABLE III

Ratio of Forces in Normal Subjects and in Cases with Myocardial Infarction

\begin{tabular}{|c|c|c|}
\hline & Initial rightward forces & Initial superior forces \\
\hline & Subsequent leftward forces & Subsequent inferior force \\
\hline Normal. . $\quad \ldots \quad \ldots$ & $\begin{array}{r}0-0.224 \\
\text { Av. } 0.09\end{array}$ & $\begin{array}{c}0-0.273 \\
\text { Av. } 0.99\end{array}$ \\
\hline Lateral infarction & $0 \cdot 3-2 \cdot 0$ & 一 \\
\hline Posterior infarction $\quad$. & - & $0 \cdot 3-0$ \\
\hline Post.-septal infarction. . & - & $0.66-0$ \\
\hline
\end{tabular}

It does appear from our results that the direction of the 0.015 second vector has considerable diagnostic value, except in lateral infarction where measurement of the ratio of the magnitude of rightward to leftward forces is of more value. However, this time interval of 0.015 seconds is an arbitrary one and it is likely that if a longer one were chosen, the method might well be of value in the diagnosis of lateral infarction also.

Body and Terminal Forces. It has been shown how myocardial infarction can modify the body of the QRS loop. The loop in the sagittal plane in posterior infarction is frequently of a bizarre shape, and in anterior infarction the body is narrowed and displaced posteriorly. The infinite variety in the contour of the loop makes accurate mathematical analysis difficult. Even measurement of the major QRS axis is difficult to standardise, for example, when the loop is sickle-shaped.

Although the terminal forces were analysed in detail, we have the impression that little can be gained from their study in most cases of myocardial infarction. They may, however, be important in some infarcts of unusual position.

$Q R S$ and T Loop Rotation. It was noted that in infarction involving the septum and in lateral infarction rotation of the QRS loop in the horizontal plane was often clockwise, and in posterior infarction the rotation in the frontal and sagittal planes was frequently the reverse of normal. The $T$ loop rotation appeared to be less frequently affected, though sometimes it was linear in the frontal and sagittal planes making determination of rotation difficult.

In the normal QRS loop in the frontal plane there was frequently a small initial loop inscribed in the opposite direction to the main body of the loop, corresponding to the initial forces to the right and anteriorly seen in the horizontal plane. In some instances the QRS "loop" consisted of two or more small loops. In the table the direction of rotation of the longest portion is recorded.

$Q R S / T$ Angle. The range of values in all cases of infarction was wider than normal and this measurement did not appear to be of any specific value in localizing the site of infarction.

Amplitude of $Q R S$ and $T$ Loops. There was a very wide range of values in the normal group (see table) and considerable overlap between normals and cases with infarction.

For this reason we found the measurements to be of no value. 
QRS Plane. Schellong (1939) reported his observation that in normal subjects the spatial QRS loop lies approximately in a single plane. Rochet and Vastesaeger (1939) confirmed and extended this observation, reporting the variations of normal. More recently Milnor (1957) has given quantitative expression to the QRS plane by means of the panoramic vectorcardiograph. As Milnor has pointed out, the fact that the normal spatial QRS loop lies in approximately a single plane is rather surprising. When one considers the complex structure of the ventricular musculature and the numerous possible pathways along which the depolarization impulse passes, it is surprising under these circumstances that the termini of the successive instantaneous vectors should lie in one plane.

The position of the QRS plane is of practical importance because variations of its position explain to a large extent the variability of electrocardiographic patterns in normal subjects.

Grant and Estes (1953) and Milnor (1957) suggest that rotation or variation in position of the QRS plane is not necessarily related to rotation of the anatomical position of the heart; it seems more likely to be related to natural variations in the structure of the ventricular muscle and the sequence of ventricular depolarization.

By a study of wire models, we were able to classify our cases of myocardial infarction according to Milnor (1957). Using these criteria, 11 of our patients with myocardial infarctions had vectorcardiograms that appeared to be within normal limits, and in others similar abnormalities occurred in different types of infarction (Table IV). This would suggest that this classification can offer little help in the diagnosis of myocardial infarction, but a proper evaluation will not be possible until we have more knowledge of the relationship between the QRS plane and the pathway of ventricular activation.

System of Notation. There is, at present, no general agreement about the method of viewing planes or the method of designating and measuring angles in vectorcardiography. In 1954, the Committee on Electrocardiography (American Heart Association) in their section on vectorcardiography, recommended viewing the sagittal plane from the left and the horizontal plane from

TABLE IV

Classification of the QRS Plane

\begin{tabular}{|c|c|c|c|c|}
\hline & \multirow{2}{*}{$\begin{array}{l}\text { Normal QRS plane } \\
\left(5^{\circ}-165^{\circ}\right)\end{array}$} & \multicolumn{3}{|c|}{ Abnormal QRS plane } \\
\hline & & $\begin{array}{l}\text { Outwith normal } \\
\text { range }\end{array}$ & $\begin{array}{l}\text { Abnormal } \\
\text { contour }\end{array}$ & $\begin{array}{l}\text { Bent or } \\
\text { distorted }\end{array}$ \\
\hline $\begin{array}{lll}\text { Normal } & \ldots & \ldots\end{array}$ & 50 & - & - & - \\
\hline Posterior infarction. . & 3 & - & 3 & 3 \\
\hline $\begin{array}{l}\text { Posterior and septal } \\
\text { infarction }\end{array}$ & 2 & 2 & - & 5 \\
\hline $\begin{array}{l}\text { Antero-septal } \\
\text { infarction }\end{array}$ & 6 & 3 & 5 & 12 \\
\hline Lateral infarction .. & - & - & 1 & 3 \\
\hline
\end{tabular}

above (the frontal plane is viewed from the front). Helm (1956) discussed the problem of polarity and measurement of vector angles from the trigonometric point of view and suggested two possible schemes, one of which was in agreement with the arguments put forward by Robertson (1957) that the movement of the cardiac vector towards the observer should be represented as positive. According to these workers $(a)$ the frontal plane is viewed from the front of the patient, $(b)$ the sagittal plane from the left, and $(c)$ the horizontal plane from below. The alternative scheme of Helm's is essentially that employed by Grishman and his co-workers, using the Cube system. 
TABLE V

Analysis of the Frontal Plane Vectorcardiogram of 50 Normal Subjects and 50 Patients with MYOCARDIAL INFARCTION (see footnote)

\begin{tabular}{|c|c|c|c|c|c|c|c|c|}
\hline & & & & Normal & Posterior & Postero-septal & Antero-septal & Lateral \\
\hline No. of cases & .. & .. & - & 50 & 11 & 9 & 26 & 4 \\
\hline Initial forces & .. & .. & - & 48 & 11 & 9 & 14 & 4 \\
\hline Initial direction & .. & . & $\begin{array}{l}\text { SR } \\
\text { SL } \\
\text { IR } \\
\text { IL }\end{array}$ & $\begin{array}{r}\frac{35}{13} \\
2\end{array}$ & $\begin{array}{l}11 \\
=\end{array}$ & $\begin{array}{r}3 \\
6 \\
- \\
-\end{array}$ & $\begin{array}{r}3 \\
5 \\
4 \\
14\end{array}$ & $\frac{1}{3}$ \\
\hline $\begin{array}{l}\text { Location of QRS } \\
\text { loops }\end{array}$ & and & $\mathbf{T}$ & $\begin{array}{l}1 \\
2 \\
3 \\
4\end{array}$ & $\begin{array}{l}50(50) \\
- \\
-\end{array}$ & $\begin{array}{r}9(2) \\
\quad(1) \\
2(8)\end{array}$ & $\begin{array}{r}6(4) \\
-\quad(2) \\
3(3)\end{array}$ & $\begin{array}{c}21(9) \\
(11) \\
1(5) \\
4(1)\end{array}$ & $\begin{array}{l}1 \text { (1) } \\
1 \text { (2) } \\
1(1) \\
1\end{array}$ \\
\hline QRS angle & .. & .. & - & $8^{\circ}-53^{\circ}$ & $339^{\circ}-36^{\circ}$ & $354^{\circ}-33^{\circ}$ & $264^{\circ}-31^{\circ}$ & $349^{\circ}-198^{\circ}$ \\
\hline $\mathrm{T}$ angle $\ldots$ & .. & $\ldots$ & - & $15^{\circ}-65^{\circ}$ & $301^{\circ}-12^{\circ}$ & $221^{\circ}-57^{\circ}$ & $349^{\circ}-197^{\circ}$ & $43^{\circ}-200^{\circ}$ \\
\hline QRS/T angle & .. & 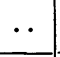 & - & $-15^{\circ}-39^{\circ}$ & $-58^{\circ}-0^{\circ}$ & $-151^{\circ}-24^{\circ}$ & $-176^{\circ}-180^{\circ}$ & $-149^{\circ}-142^{\circ}$ \\
\hline Rotation QRS & .. & .. & $\begin{array}{l}\mathrm{CC} \\
\mathrm{C}\end{array}$ & $\begin{array}{l}27 \\
23 \\
\end{array}$ & $\begin{array}{r}0 \\
11 \\
\end{array}$ & $\begin{array}{l}1 \\
8 \\
\end{array}$ & $\begin{array}{r}18 \\
8 \\
\end{array}$ & $\begin{array}{l}3 \\
1\end{array}$ \\
\hline Rotation T & . & .. & $\begin{array}{l}\mathrm{CC} \\
\mathrm{C}\end{array}$ & $\begin{array}{r}43 \\
7 \\
\end{array}$ & $\begin{array}{l}4 \\
7\end{array}$ & $\begin{array}{l}6 \\
3 \\
\end{array}$ & $\begin{array}{r}17 \\
9\end{array}$ & $\begin{array}{l}2 \\
2\end{array}$ \\
\hline QRS: $T$ rotation. & & .. & $\begin{aligned} \mathrm{CC} & : \mathrm{CC} \\
\mathrm{CC} & : \mathrm{CC} \\
\mathrm{C} & : \mathrm{C} \\
\mathrm{C} & : \mathrm{CC}\end{aligned}$ & $\begin{array}{r}32 \\
8 \\
3 \\
7\end{array}$ & $\begin{array}{l}0 \\
0 \\
7 \\
4\end{array}$ & $\begin{array}{l}1 \\
0 \\
4 \\
4\end{array}$ & $\begin{array}{r}11 \\
7 \\
2 \\
6\end{array}$ & $\begin{array}{l}1 \\
2 \\
0 \\
1\end{array}$ \\
\hline
\end{tabular}

Footnote to Tables $\mathrm{V}, \mathrm{VI}$, and $\mathrm{VII}$

$\mathrm{S}=$ superior; $\mathrm{I}=$ inferior; $\mathrm{R}=$ right $\mathrm{L}=$ left; $\mathrm{A}=$ anterior; $\mathrm{P}=$ posterior. The figures describing the location of QRS and T loops refer to the quadrants in which these loops lie; the figures surrounded by brackets refer to the T loop and the figures without brackets to the QRS loop. The angles are measured in degrees (see Fig. 1). C=clockwise rotation; C.C. $=$ counter-clockwise rotation (for further details, see text).

We decided to use the Cube system, and the method of viewing adopted by Grisham and Scherlis (1952) but we have recorded QRS and T angles over the range of $0^{\circ}-360^{\circ}$. This is the method described by Helm (1956) (Fig. 1).

The differentiation of myocardial infarction from left ventricular hypertrophy and strain, particularly when the two are combined, presents difficulties.

In anterior (antero-septal) infarction the loss of the anterior forces leads to a more posterior displacement of the loop, thus simulating the effect of left ventricular strain, and the frequently associated lateral ischæmia gives rise to a large QRS/T angle, also found in left ventricular strain. It would be expected that the degree of posterior displacement, and the magnitude of the maximum QRS vector, would be greater in left ventricular strain than in infarction. Wolff (1955) pointed out that, if hypertrophy occurs in cases with anterior infarction, it must involve the uninfarcted muscle fibres of the lateral and posterior walls. These changes would have the same effect on the mid and late cardiac vectors as anterior infarction, causing augmentation of the electrical forces in a posterior and superior direction away from the electrically inert area of anterior wall. This, however, would not affect the configuration of the initial or earlier forces, which would remain diagnostic of anterior infarction. He found that the abnormalities in the maximum vector and QRS angles in the horizontal plane are similar in left ventricular hypertrophy and anterior infarction, but that the loop in infarction is much narrower, presumably because alteration in the initial forces essentially affects the 
TABLE VI

Analysis of the Horizontal Plane Vectorcardiogram of 50 Normal Subjects and 50 Patients with MYOCARDIAL INFARCTION (see footnote)

\begin{tabular}{|c|c|c|c|c|c|c|c|c|}
\hline & & & & Normal & Posterior & Postero-septal & Antero-septal & Lateral \\
\hline No. of cases & . & $\ldots$ & - & 50 & 11 & 9 & 26 & 4 \\
\hline Initial forces & . & $\ldots$ & - & 48 & 10 & 3 & 7 & 4 \\
\hline Initial direction & . &. & $\begin{array}{l}\mathrm{AR} \\
\mathrm{AL} \\
\mathrm{PR} \\
\mathrm{PL}\end{array}$ & $\begin{array}{r}48 \\
2 \\
1 \\
- \\
\end{array}$ & $\begin{array}{c}\frac{11}{0} \\
0 \\
0\end{array}$ & $\frac{1}{2}$ & $\begin{array}{r}4 \\
1 \\
3 \\
18\end{array}$ & $\begin{array}{l}4 \\
- \\
-\end{array}$ \\
\hline $\begin{array}{l}\text { Location of QRS } \\
\text { loops }\end{array}$ & and o & & $\begin{array}{l}1 \\
2 \\
3 \\
4\end{array}$ & $\begin{array}{l}13(40) \\
\frac{\overline{3}}{37}(10)\end{array}$ & $\begin{array}{r}2(8) \\
-\quad(1) \\
9(2)\end{array}$ & $\begin{array}{r}(3) \\
-\quad(3) \\
9(3)\end{array}$ & $\begin{array}{r}(6) \\
(14) \\
(2) \\
26(4)\end{array}$ & $\begin{array}{l}-\overline{2}(3) \\
2\end{array}$ \\
\hline QRS angle & .. &. & - & $332^{\circ}-11^{\circ}$ & $335^{\circ}-4^{\circ}$ & $318^{\circ}-356^{\circ}$ & $290^{\circ}-354^{\circ}$ & $314^{\circ}-135^{\circ}$ \\
\hline T angle.. & $\cdots$ & $\cdots$ & - & $342^{\circ}-55^{\circ}$ & $322^{\circ}-80^{\circ}$ & $328^{\circ}-139^{\circ}$ & $8^{\circ}-356^{\circ}$ & $312^{\circ}-164^{\circ}$ \\
\hline QRS/T angle & $\cdots$ & $\cdots$ & - & $-11^{\circ}-49^{\circ}$ & $-32^{\circ}-62^{\circ}$ & $0^{\circ}-175^{\circ}$ & $-177^{\circ}-180^{\circ}$ & $-165^{\circ}-11^{\circ}$ \\
\hline Rotation QRS & . & $\ldots$ & $\begin{array}{l}\mathrm{CC} \\
\mathrm{C}\end{array}$ & 50 & $\begin{array}{r}11 \\
0\end{array}$ & $\begin{array}{l}4 \\
5 \\
\end{array}$ & $\begin{array}{l}13 \\
13 \\
\end{array}$ & $\begin{array}{l}1 \\
3 \\
\end{array}$ \\
\hline Rotation $\mathrm{T}$ & .. & $\ldots$ & $\begin{array}{l}\mathrm{CC} \\
\mathrm{C}\end{array}$ & 50 & $\begin{array}{r}11 \\
0\end{array}$ & $\begin{array}{l}8 \\
1 \\
\end{array}$ & $\begin{array}{l}15 \\
11\end{array}$ & $\begin{array}{l}2 \\
2\end{array}$ \\
\hline QRS: $\mathrm{T}$ rotation & & .. & $\begin{array}{c}\mathrm{CC}: \mathrm{CC} \\
\mathrm{CC}: \mathrm{CC} \\
\mathrm{C}: \mathrm{C} \\
\mathrm{C}: \mathrm{C}\end{array}$ & $\begin{array}{l}50 \\
\text { - } \\
-\end{array}$ & $\frac{11}{-}$ & $\begin{array}{r}3 \\
1 \\
5\end{array}$ & $\begin{array}{l}7 \\
6 \\
5 \\
8\end{array}$ & $\frac{1}{2}$ \\
\hline
\end{tabular}

efferent portion of the QRS loop. He also found that in left ventricular hypertrophy and left bundlebranch block, QRS and T loops were inscribed in the same direction, whereas in anterior infarction the two were usually inscribed in opposite directions.

When the infarction is confined entirely to the inferior or posterior surface, the horizontal plane shows no abnormality. When lateral ischæmia is present in addition then the QRS/T angle in the horizontal plane will be increased but theoretically there should be no displacement of the loop posteriorly as would be expected with left ventricular hypertrophy.

In lateral myocardial infarction, the distortion of the loop in the horizontal plane, due to loss of forces on the lateral or left surface of the heart, obscures the change that might arise from an associated left ventricular hypertrophy.

In 33 of our patients infarction involved the septum and 7 of these had previously had hypertension (diastolic pressure greater than $95 \mathrm{~mm} . \mathrm{Hg}$ ) or had hypertension at the time the tracing was taken. The QRS angle in the horizontal plane in these seven varied between $290^{\circ}$ and $336^{\circ}$. In two the angle was less than $315^{\circ}$ which was the position of the most posteriorly placed QRS vector in the normal and posterior infarction groups.

Of the 26 cases with normal blood pressure the QRS was below $315^{\circ}$ in only one. The QRS angle for these 26 cases was $304^{\circ}-356^{\circ}$ (normal $315^{\circ}-11^{\circ}$ ), indicating that the QRS vector in septal infarction lies in the more posterior range of normal.

Comparison of Electrocardiography and Vectorcardiography. The most obvious question that arises from a study of vectorcardiography, whether it be in myocardial infarction or any other type of heart disease, is whether vectorcardiography has any advantage over electrocardiography.

Den Boer (1952) concluded that the vectorcardiogram had not been found useful in the diagnosis 
TABLE VII

Analysis of the Sagittal Plane Vectorcardiogram of 50 Normal Subjects and 50 Patients with MYOCARDIAL INFARCTION (see footnote)

\begin{tabular}{|c|c|c|c|c|c|c|c|c|}
\hline & & & & Normal & Posterior & Postero-septal & Antero-septal & Lateral \\
\hline No. of cases & .. & $\ldots$ & - & 50 & 11 & 9 & 26 & 4 \\
\hline Initial forces & . & .. & - & 34 & 11 & 9 & 8 & 1 \\
\hline Initial direction & .. & .. & $\begin{array}{l}\text { AS } \\
\text { AI } \\
\text { PS } \\
\text { PI }\end{array}$ & $\begin{array}{l}34 \\
16 \\
-\end{array}$ & $\begin{array}{l}11 \\
=\end{array}$ & $\frac{1}{8}$ & $\begin{array}{r}- \\
5 \\
8 \\
13\end{array}$ & $\begin{array}{r}1 \\
3 \\
-\end{array}$ \\
\hline \multicolumn{3}{|c|}{$\begin{array}{l}\text { Location of QRS and of T } \\
\text { loops }\end{array}$} & $\begin{array}{l}1 \\
2 \\
3 \\
4\end{array}$ & $\begin{array}{l}17(34) \\
32(16) \\
1 \\
-\end{array}$ & $\begin{array}{l}(3) \\
5(1) \\
5(1) \\
1(6) \\
\end{array}$ & $\begin{array}{l}(2) \\
4(2) \\
(3) \\
\end{array}$ & $\begin{array}{l}\text { (17) } \\
17(5) \\
6 \\
2\end{array}$ & $\begin{array}{l}1(2) \\
1(2) \\
1 \\
1\end{array}$ \\
\hline QRS angle & $\cdots$ & $\cdots$ & - & $58^{\circ}-154^{\circ}$ & $90^{\circ}-281^{\circ}$ & $144^{\circ}-250^{\circ}$ & $9^{\circ}-352^{\circ}$ & $338^{\circ}-240^{\circ}$ \\
\hline T angle .. & $\cdots$ & $\cdots$ & - & $30^{\circ}-125^{\circ}$ & $241^{\circ}-23^{\circ}$ & $6^{\circ}-330^{\circ}$ & $310^{\circ}-128^{\circ}$ & $2^{\circ}-180^{\circ}$ \\
\hline QRS/T angle & $\cdots$ & $\cdots$ & - & $-63^{\circ}-86^{\circ}$ & $-174^{\circ}-179^{\circ}$ & $-94^{\circ}-160^{\circ}$ & $-175^{\circ}-153^{\circ}$ & $-129^{\circ}-150^{\circ}$ \\
\hline Rotation QRS & . & .. & $\mathrm{CC}$ & $\begin{array}{r}1 \\
49\end{array}$ & $\begin{array}{l}9 \\
2\end{array}$ & $\begin{array}{l}8 \\
1\end{array}$ & $\begin{array}{r}9 \\
17\end{array}$ & $\begin{array}{l}0 \\
4\end{array}$ \\
\hline Rotation $\mathrm{T}$ & . & . & $\begin{array}{l}\mathrm{CC} \\
\mathrm{C}\end{array}$ & $\overline{50}$ & $\begin{array}{l}6 \\
5 \\
\end{array}$ & $\begin{array}{l}1 \\
8\end{array}$ & $\begin{array}{l}10 \\
16 \\
\end{array}$ & $\begin{array}{l}3 \\
1\end{array}$ \\
\hline QRS: $\mathrm{T}$ rotation & & .. & $\begin{array}{c}\mathrm{CC}: \mathrm{CC} \\
\mathrm{CC}: \mathrm{C} \\
\mathrm{C}: \mathrm{C} \\
-\end{array}$ & $\begin{array}{r}-1 \\
49 \\
-\end{array}$ & $\begin{array}{r}4 \\
5 \\
2\end{array}$ & $\begin{array}{r}1 \\
7 \\
1 \\
\end{array}$ & $\begin{array}{r}3 \\
6 \\
10 \\
7\end{array}$ & $\begin{array}{l}0 \\
0 \\
1 \\
3\end{array}$ \\
\hline
\end{tabular}

of myocardial infarction but was of great help in understanding the electrical phenomena in this condition. In particular, he states, infarctions that are manifested in the chest leads only have no characteristic vectorcardiogram. He also claims that vectorcardiograms in left ventricular hypertrophy may be indistinguishable from the vectorcardiograms in antero-septal infarction.

Grishman (1954) points out that, with the vector concept, the older theory of the origin of the $\mathrm{Q}$ wave in the electrocardiogram being due to a "window effect" reflecting the potential of the left ventricular cavity, through an inert portion (infarct) of the ventricular wall, is no longer tenable. He claims that the electrocardiogram, in certain cases of infarction, does not show $Q$ waves and the vectorcardiogram is more likely to reveal abnormality in that it shows a displacement away from the affected area. He concludes that the vectorcardiogram can help to diagnose myocardial infarction more frequently than the electrocardiogram.

Wolff (1955) concluded after a study of 50 cases, with autopsy data, that vectorcardiography was superior in the localization of infarction, anterior, posterior, or septal, and in the detection of multiple infarcts. Young et al. (1956) in a study of 30 cases of inferior infarction, with limited postmortem confirmation, were also of the opinion that vectorcardiography is more accurate.

In a study of only 50 cases it would be impossible for us to give a definite opinion as to which method is superior, but certain tentative conclusions can be drawn. In the first place, vectorcardiography and electrocardiography are merely different forms of presentation of the same electrical forces; electrocardiograms are a scalar function of time, vectorcardiograms are a vector function of time. The one form of recording may show certain features more readily than the other and vice versa; the one does not replace the other; they are complementary. In the second place, the method of analysis at present favours electrocardiography in that quantitative measurements, 
especially of time, are most readily made; in vectorcardiography quantitative measurements may be extremely difficult in certain cases. Furthermore, there is, at present, in vectorcardiography no general agreement as to which is the best reference system or the best system of notation or the best quantitative measurements.

There is little doubt, however, that vectorcardiography has been very valuable in understanding and providing a rational explanation for the changes found in electrocardiography. Our impressions are that, at present, there is little to choose between the two methods in the diagnosis of myocardial infarction in its usual locations-septal, posterior, and lateral. In certain ways, electrocardiography is superior, e.g. in cases of acute myocardial infarction.

The main test as to the superiority of the one method over the other does not appear to lie in the ability of either to diagnose the more commonly occurring infarctions but in those listed in the introductory paragraph where diagnosis by electrocardiography is known to be difficult.

We have not attempted to study, in particular, the role of vectorcardiography in the diagnosis of multiple infarcts, in the diagnosing of infarctions in unusual sites, or in the differentiation of infarction from pericarditis. In the present series we had little difficulty in diagnosing myocardial infarction associated with right bundle-branch block, but the electrocardiographic tracings produced no great difficulties either; it will be interesting, however, to see if vectorcardiography has any greater diagnostic value than electrocardiography in the diagnosis of myocardial infarction associated with left bundle-branch block.

\section{SUMMARY}

The vectorcardiograms of 50 patients with myocardial infarction and of 50 normal subjects have been analysed.

The problems of analysis, qualitative and quantitative, and of notation and system of recording have been discussed. The merits of electrocardiography and vectorcardiography in the diagnosis of myocardial infarction have been compared. There is little to choose between the two methods in the majority of cases, but it would be desirable to investigate further the value of vectorcardiography in those presenting most difficulties in electrocardiographic diagnosis, and preferably with necropsy control.

We should like to thank Dr. J. H. Wright for his permission to use the patients under his care, and for his helpful criticism. We should also like to acknowledge the valuable comments made by Dr. Douglas Robertson in the preparation of this paper.

\section{REFERENCES}

den Boer, W. (1952). Acta med. Scand., 144, 217.

Duchosal, P. W., and Sulzer, R. (1949). La Vectocardiographie. Karger, Basle.

Goldberger, F. (1957). Unipolar Electrocardiography and Vectorcardiography. Lea \& Febiger, Philadelphia.

Grant, R. P., and Estes, E. H. (1953). Circulation, 7, 890.

Grishman, A. (1954). Recent Advances in Internal Medicine. Saunders, Philadelphia.

Grishman, A., and Scherlis, L. (1952). Spatial Vectorcardiography. Saunders, Philadelphia.

Helm, R. A. (1956). Circulation, 13, 581.

Milnor, W. R. (1957). Circulation, 1, 95.

$\longrightarrow$, Genecin, A., Talbot, S. A., and Newman, E. V. (1951). Johns Hopk. Hosp. Bull., 89, 291.

Myers, G. B., Klein, H. A., and Heratzke, T. (1949). Amer. Heart J., 38, 547.

Pearce, M. L., and Chapman, M. L. (1957). Amer. Heart J., 53, 782.

Robertson, D. (1957). Amer. Heart J., 53, 247.

Rochet, J., and Vastesaeger, M. M. (1939). Arch. int. Physiol., 49, 113.

Schellong, F. (1939). Grundzüge einer klinischen Vektorkardiographie des Herzens. Springer, Berlin.

Wolff, L. (1955). Dis. Chest., 27, 263.

Young, E., Wolff, L., and Chatfield, J. (1956). Amer. Heart J., 51, 713.

Young, E., and Karlen, (1956). Amer. Heart J. 52, 232. 